\title{
Tanshinone IIA reduces secretion of pro-angiogenic factors and inhibits angiogenesis in human colorectal cancer
}

\author{
LIHONG ZHOU ${ }^{1,2^{*}}$, HUA SUI ${ }^{2 *}$, TING WANG $^{2}$, RU JIA $^{2}$, ZHAOZHOU ZHANG $^{2}$, JIE FU $^{2}$, YUANYUAN FENG $^{2}$ \\ NINGNING LIU ${ }^{2}$, QING JI ${ }^{2}$, YAN WANG ${ }^{2}$, BIMENG ZHANG ${ }^{3}, \mathrm{QI} \mathrm{LI}^{2}$ and $\mathrm{YAN} \mathrm{LI}^{1}$ \\ ${ }^{1}$ Department of Oncology, Shanghai Municipal Hospital of Traditional Chinese Medicine, Shanghai University of \\ Traditional Chinese Medicine, Shanghai 200071; ${ }^{2}$ Department of Medical Oncology, Shuguang Hospital, \\ Shanghai University of Traditional Chinese Medicine, Shanghai 201203; ${ }^{3}$ Department of Acupuncture, \\ Shanghai General Hospital, Shanghai Jiao Tong University, Shanghai 201620, P.R. China
}

Received January 14, 2019; Accepted January 24, 2020

DOI: $10.3892 /$ or.2020.7498

\begin{abstract}
Tumor angiogenesis is an important factor which precipitates recurrence and metastasis of colorectal cancer (CRC). Angiogenesis is also a significant feature which accompanies invasion and metastasis of CRC. Tumor hypoxia activates hypoxia inducible factor (HIF), which promotes angiogenesis in CRC. HIF significantly promotes cell proliferation and angiogenesis in CRC, facilitating invasion and metastasis. Tanshinone IIA (Tan IIA) has been revealed to effectively inhibit angiogenesis in CRC, although the underlying mechanism remains to be determined. The aim of the present study was to determine the effects of HIF-1 $\alpha$ on hypoxia induced angiogenesis in CRC cells, the effects of Tan IIA on the expression of pro-angiogenic factors in CRC cells, and on human umbilical vein endothelial cell (HUVEC) tube formation in normal and hypoxic conditions. The results of the present study revealed that Tan IIA not only decreased HIF-1 $\alpha$ expression and inhibited the secretion level of vascular endothelial growth factor and basic fibroblast growth factor, but also efficiently decreased proliferation, tube formation and metastasis of HUVECs. The results highlight the potential of Tan IIA-mediated targeting of HIF- $1 \alpha$ as a potential therapeutic option for treatment of patients with CRC.
\end{abstract}

Correspondence to: Dr Yan Li, Department of Oncology, Shanghai Municipal Hospital of Traditional Chinese Medicine, Shanghai University of Traditional Chinese Medicine, 274 Middle Zhijiang Road, Shanghai 200071, P.R. China

E-mail: 18916767226@163.com

Dr Qi Li, Department of Medical Oncology, Shuguang Hospital, Shanghai University of Traditional Chinese Medicine, 528 Zhangheng Road, Shanghai 201203, P.R. China

E-mail: lzwf@hotmail.com

*Contributed equally

Key words: tanshinone IIA, colorectal cancer, pro-angiogenic factors, hypoxic microenvironment, angiogenesis

\section{Introduction}

Colorectal cancer (CRC) is one of the most frequently observed substantive malignancies in clinical operations. CRC is the third most common cancer among male patients and the second most common cancer among female patients worldwide. The mortality rate among male patients is the fourth highest and for female patients it is the third highest among all types of cancer worldwide (1). The incidence and mortality rates have been increasing annually over the past two decades. Research on postoperative prevention and treatment of CRC has resulted in improvements to treatments; however, the 5-year survival rate has not improved significantly. One of the major challenges in treating CRC is tumor neovascularization which results in invasion and metastasis of CRC to other organ tissues $(2,3)$. Tumor angiogenesis is one of the primary means by which CRC invades and metastasizes, and frequently accompanies invasion and metastasis of CRC.

Hypoxia is a frequently observed pathological state in solid tumors. Rapid proliferation of CRC cells results in local tumor tissues becoming hypoxic, and activating the core hypoxia response factor, upregulation of hypoxia inducible factor $1 \alpha$ (HIF-1 $\alpha$ ). HIF- $1 \alpha$ is a basic regulatory factor of tumor angiogenesis during hypoxic conditions. It is composed of a heterodimer of $\alpha$ and $\beta$ subunits. The hypoxic microenvironment results in activation of HIF-1 $\alpha$ in tumor cells, which in turn upregulates the expression of pro-angiogenic factors such as vascular endothelial growth factor (VEGF) $(4,5)$ and basic fibroblast growth factor (bFGF) (6), which increase vascularization in the solid tumor, and participate in multiple aspects of tumor formation. Therefore, HIF-1 $\alpha$ expression levels in tissues and cells can be used as a key indicator when monitoring tumor neovascularization (7) and HIF-1 $\alpha$-based antineoplastic drug filtering (8). It is also a key indicator used to evaluate the effectiveness of clinical tumor neovascularization treatments (9).

Tanshinone IIA (Tan IIA) is the active ingredient of Salvia, a traditional Chinese medicine, which inhibit growths, induces apoptosis and reverses multidrug resistance in various types of human cancer cells. However, there are relatively fewer studies investigating the effects of Tan IIA on tumor neovasculariza- 
tion and its underlying mechanisms. In our previous study, it was demonstrated that Tan IIA inhibited angiogenesis in a CRC mouse model (10). Tan IIA also decreased VEGF expression levels in CRC cells by downregulating the expression of COX-2 (11). Hypoxia-induced tumor neovascularization is frequently observed in CRC clinically and pre-empts CRC angiogenesis. Therefore, the aim of the present study was to determine the effect of Tan IIA on hypoxia and the underlying signaling pathways modulated by Tan IIA.

The aim of the present study was to provide an understanding of the means by which Tan IIA prevented angiogenesis. A previously established HIF-1 $\alpha$ overexpression vector and an HIF-1 $\alpha$ RNA interference plasmid were used to determine the effects of Tan IIA on the expression of pro-angiogenic factors in CRC cells and tube formation in human umbilical vein endothelial cells (HUVECs) in normal and hypoxic conditions.

\section{Materials and methods}

Lentivirus plasmid. The lentiviral vector pGC-FU and pGC-FU-HIF-1 $\alpha$ were used for HIF-1 $\alpha$ overexpression studies. A eukaryotic vector plasmid containing small interfering (si)R-Mimic was used as a control and three plasmids containing different siRNA (siR) sequences targeting HIF-1 $\alpha$ were used for knockdown experiments. All plasmids were purchased from Shanghai GeneChem Co., Ltd.

Cell culture. Human CRC HCT-116 cells were purchased from The Cell Bank of Type Culture Collection of the Chinese Academy of Sciences and cultured in RPMI-1640 medium containing $10 \%$ fetal calf serum. HUVECs, were obtained from The Experiment Center of Putuo Hospital affiliated to Shanghai University of Chinese Medicine and were cultured in endothelial cell medium containing $15 \%$ fetal calf serum. Both cell lines were incubated at $5 \% \mathrm{CO}_{2}$ at $37^{\circ} \mathrm{C}$.

Reagents. Tan IIA (98\% pure) was purchased from Xi'an Guanyu Bio-Tech Co., Ltd. and cobalt chloride $\left(\mathrm{CoCl}_{2}\right)$ was obtained from Sigma-Aldrich; Merck KGaA.

Lentiviral infection of HCT-116 cells. HCT-116 cells were routinely cultured and during the logarithmic phase were plated into a $24-w e l l$ plate at a density of $1 \times 10^{5}$ cells $/ \mathrm{ml}$. Cells were divided into the following four conditions: Blank group, $\mathrm{CoCl}_{2}$ group, pGC-FU vector group and pGC-FU-HIF-1 $\alpha$ group; with three wells per condition. Cells were incubated until confluence had reached $30-50 \%$. For infection, $1 \times 10^{8} \mathrm{TU} / \mathrm{ml} \mathrm{pGC}-\mathrm{FU}$ vector or pGC-FU-HIF-1 $\alpha$ lentivirus was added to $60 \mu \mathrm{l}$ culture medium and this mix was added to each well. After 8-12 h, the state of the cells was observed, and the culture medium was replaced with fresh medium. A total of $48 \mathrm{~h}$ after infection, fluorescence was observed and subsequent experiments were performed.

siR-HIF-1 $\alpha$ transfection of HTC-116 cells. A total of $5 \times 10^{5}$ cells/ml HCT-116 cells were plated per well in a 6 -well plate. Cells were divided into the following six conditions: Blank group, $\mathrm{CoCl}_{2}$ group, siR-mimic group, siR-HIF-1 $\alpha$ sequence $1+\mathrm{CoCl}_{2}$ group, siR-HIF-1 $\alpha$ sequence $2+\mathrm{CoCl}_{2}$ group and siR-HIF- $1 \alpha$ sequence $3+\mathrm{CoCl}_{2}$ group; with three wells per condition. Cells were incubated until confluence had reached $40-60 \%$. A mixture containing $4 \mu \mathrm{g}$ of DNA and $12 \mu \mathrm{l}$ of HilyMax was added to $100 \mu \mathrm{l}$ serum-free medium and sufficiently mixed. The mixture was incubated at room temperature for $15 \mathrm{~min}$ and subsequently added to the wells, which were cultured for 8-12 h. The medium was replaced with fresh medium and incubated for a further $48 \mathrm{~h}$. Transfection was confirmed by observing fluorescence expression under a fluorescent microscope.

Reverse transcription-quantitative (RT-q)PCR. HCT-116 cells transfected with the various siRNAs were used for RT-qPCR. The medium from cells treated with $\mathrm{CoCl}_{2}$ was replaced with fresh medium containing $200 \mu \mathrm{M} \mathrm{CoCl}_{2}$ and incubated for $48 \mathrm{~h}$. Subsequently, a total RNA extraction kit was used to extract RNA according to the manufacturer's protocol. RNA purity and concentration were determined. For reverse transcription, $4 \mu 1$ 5X PrimeScript Buffer, $1 \mu$ l PrimeScript RT Enzyme Mix I, $1 \mu \mathrm{l}$ Oligo dT Primer (50 $\mu \mathrm{mol} / \mathrm{l}), 1 \mu \mathrm{l}$ random hexamers $(100 \mu \mathrm{mol} / \mathrm{l})$ and $4 \mu \mathrm{l}$ of total RNA were added and brought to a final volume of $20 \mu \mathrm{l}$ using Rnase-free water. The reverse transcription temperature protocol was as follows: $37^{\circ} \mathrm{C}$ for $15 \mathrm{~min}$ and then $85^{\circ} \mathrm{C}$ for $5 \mathrm{sec}$. The primer sequences used were: HIF-1 $\alpha$ forward, 5'-CGAAGTAGTGCT GACCCTGC-3' and reverse, 5'-AACTTTGTCTAGTGCTTC CATCG-3'; HIF-1 $\alpha$ probe, 5'-AGGTGTCTGATCCTGAAT CTGGGGCA-3'; GAPDH forward, 5'-CCACTCCTCCAC CTTTGAC-3' and reverse, 5'-ACCCTGTTGCTGTAGCCA-3', GAPDH probe; 5'-TTGCCCTCAACGACCACTTTGTC-3'. All primers were synthesized by Sangon Biotech Co., Ltd. For qPCR, a solution containing $0.4 \mu \mathrm{l}$ each of forward and reverse primers, $0.8 \mu \mathrm{l}$ probe, $2 \mu \mathrm{l} \mathrm{cDNA}, 0.4 \mu \mathrm{l}$ Rox Reference Dye and $10 \mu \mathrm{l}$ Premix EX Taq was prepared. The solution was brought to a final volume of $20 \mu \mathrm{l}$ using $\mathrm{dH}_{2} \mathrm{O}$. The thermocycling conditions were as follows: Pre-denaturation, $94^{\circ} \mathrm{C}$ for $10 \mathrm{sec}$; followed by 40 cycles of denaturation, $95^{\circ} \mathrm{C}$ for $5 \mathrm{sec}$, annealing at $60^{\circ} \mathrm{C}$ and extension for $34 \mathrm{sec}$. PCR was performed using an ABI 7300 SDS. GAPDH was used as an internal reference. HIF-1 $\alpha$ relative mRNA expression levels were calculated using the $2^{-\Delta \Delta \mathrm{Cq}}$ method (DCq=HIF-1 $\alpha$ Cq-GAPDH Cq) (12).

Cell proliferation assay. A total of $5 \times 10^{3} \mathrm{HCT}-116$ cells/well were plated in a 96 well plate (12 wells per condition) and cultured overnight. Once the cells had adhered, 2, 4, 8, 16, 32, and $64 \mu \mathrm{M}$ of Tan IIA were added to the cells cultured under normal conditions. Additionally, 1, 5, 10, 15 and $20 \mu \mathrm{M}$ of Tan IIA were added to the cells cultured under hypoxic conditions (simulated using $200 \mu \mathrm{M}$ of $\mathrm{CoCl}_{2}$ ). Cells were cultured for 24, 48 and $72 \mathrm{~h}$, and HCT-116 medium was routinely collected. ECM containing $15 \%$ FBS was used to produce 5 different volume concentrations $(6.25,12.5,25,50$ and $75 \%$ HCT-116 medium in the cell culture). Subsequently, $1 \times 10^{3}$ cells $/ \mathrm{ml}$ were plated per well in a 96 well plate. Once the cells had adhered, the tumor supernatant cultures were replaced with 5 gradient concentrations of HCT-116 medium. The cells were cultured for $48 \mathrm{~h}$ after which $20 \mu \mathrm{l} \mathrm{CCK}-8$ solution was added to each well, and cultured for a further $4 \mathrm{~h}$. Absorbance was measured using a microplate reader at $450 \mathrm{~nm} / 630 \mathrm{~nm}$. Growth inhibi- 
tion rate (GIR) was calculated using the following equation: $\mathrm{GIR}=[1-(\mathrm{ODn}-\mathrm{OD} 0) /(\mathrm{ODc}-\mathrm{OD} 0)] \mathrm{x} 100 . \mathrm{OD}_{0}$ was the absorbance in the blank group. $\mathrm{OD}_{c}$ was the absorbance of the normal control group. $\mathrm{OD}_{\mathrm{n}}$ was the absorbance of cells treated with the various doses of Tan IIA. The $\mathrm{IC}_{50}$ of Tan IIA was calculated. Experiments were repeated three times independently.

ELISA detection of VEGF and bFGF. A total $0.5 \mathrm{ml}$ $1 \times 10^{5}$ cells $/ \mathrm{ml}$ suspension was plated per well. Cells were divided as follow: Blank group, $\mathrm{CoCl}_{2}$ group, $\mathrm{pGC}-\mathrm{FU}$ vector group, pGC-FU HIF-1 $\alpha$ group, siR-mimic group, siR-HIF-1 $\alpha$ group, siR-HIF-1 $\alpha+\mathrm{CoCl}_{2}$ group, Tan IIA-L group $(2.5 \mu \mathrm{M})$, Tan IIA-M group (5 $\mu \mathrm{M})$, Tan IIA-H group $(10 \mu \mathrm{M})$ and Tan IIA-M $+\mathrm{CoCl}_{2}$ group. Cells were treated 5 gradient concentrations of HCT-116 medium. To simulate hypoxia, $200 \mu \mathrm{M}$ of $\mathrm{CoCl}_{2}$ was added in the $\mathrm{CoCl}_{2}$ group and cells were incubated. After $48 \mathrm{~h}$, the supernatant from each well was collected in a sterile area. The supernatant was centrifuged at $626 \mathrm{x}$ g for $10 \mathrm{~min}$ to remove the cell debris. Specific ELISA kits were used measure the expression levels of VEGF and bFGF according to the manufacturer's protocol and experiments were repeated three times.

Western blotting. Total proteins were extracted from cells with Nuclear and Cytoplasmic Protein Extraction kit (P0027; Beyotime Institute of Biotechology) and protein detected with Enhanced BCA Protein Assay kit (P0010; Beyotime Institute of Biotechology). Lysates were diluted to a protein concentration of $5 \mu \mathrm{g} / \mu \mathrm{l}$ and $60 \mu \mathrm{g}$ of protein samples were resolved on a $10 \%$ gel using SDS-page. Proteins were transferred to PVDF membranes (EMD Millipore) using a Bio-Rad Trans-Blot (Bio-Rad Laboratories, Inc.) at $100 \mathrm{mV}$ and $135 \mathrm{~mA}$. Membranes were blocked in 5\% skimmed milk at room temperature for $2 \mathrm{~h}$ or at $4^{\circ} \mathrm{C}$ overnight. Subsequently, the membranes were incubated in 5\% BSA solution with a HIF-1 $\alpha$ primary antibody (cat. no. 3716S; dilution 1:500; Cell Signaling Technology, Inc.) for $2 \mathrm{~h}$ at room temperature or overnight at $4^{\circ} \mathrm{C}$. Subsequently, the membranes were washed with TBS-Tween four times, $10 \mathrm{~min}$ each, after which the membranes were incubated with the secondary horseradish peroxidase-conjugated anti-goat antibody (cat. no. HAF109; dilution 1:1,000; R\&D Systems China Co., Ltd.) or anti-rabbit antibody (cat. no. HAF008; dilution 1:1,000; R\&D Systems China Co., Ltd.) at room temperature for $2 \mathrm{~h}$. The membranes were washed six times using TBS-Tween. Signals were visualized using by adding enhanced chemiluminescent reagent (EMD Millipore) for 1-2 min, and X-ray films were exposed to the membranes and developed. Densitometry analysis was performed using ImageJ (National Institutes of Health).

Flow cytometry. A total of $1.5 \times 10^{6} \mathrm{HCT}-116$ cells were plated well in a 6-well plate and allowed to adhere. Medium containing $200 \mu \mathrm{M}$ of $\mathrm{CoCl}_{2}$ and $2.5,5$ or $10 \mu \mathrm{M}$ Tan IIA was added. Cells were further cultured for $24 \mathrm{~h}$, after which the medium was removed, the cells were trypisinized, resuspended and fixed. A total of $200 \mu \mathrm{l}$ of cells at a density of $5 \times 10^{5}$ were incubated with phycoerythrin-labeled anti-HIF-1 $\alpha$ antibody (cat. no. 79233; dilution 1:1,600; Cell Signaling Technology, Inc.). As the blank control, $200 \mu$ l PBS was used. Cells were incubated on ice for $40 \mathrm{~min}$ in the dark with the antibody and subsequently fixed with $500 \mu \mathrm{l}$ of $70 \%$ ethanol. Fluorescence was measured using a flow cytometer (BD Biosciences).

Tube formation assay. HUVECs were divided into separate groups as follows: HCT-116 group, pGC-FU vector group, pGC-FU-HIF-1 $\alpha$ group, siR-mimic group, siR-HIF-1 $\alpha$ group, $\mathrm{CoCl}_{2}$ group, siR-HIF-1 $\alpha+\mathrm{CoCl}_{2}$ group and 1.0, 2.5, 5.0 or $10 \mu \mathrm{M}$ Tan IIA groups, with three wells per condition. A suspension of HUVECs at a density of $1 \times 10^{5}$ cells $/ \mathrm{ml}$ single-cell suspension in serum-free ECM, were plated in a 48-well plate pre-coated with $200 \mu 1$ Matrigel. After the cells had adhered, medium from one of the groups above or $200 \mu 1$ of tumor medium was added and cells were cultured. Tube formation of HUVECs was observed and imaged under an Olympus CKX41 inverted microscope (magnification x100; Olympus Corp.) and three images were obtained per well.

Migration assays. A total of $200 \mu \mathrm{l}$ single-cell suspension of HUVECs in ECM at a density of $6 \times 10^{5} / \mathrm{ml}$ were added to the upper chamber of a Transwell insert. Tan IIA $(1.0,2.5,5$ or $10 \mu \mathrm{M})$ was added to the wells. In the bottom chamber, $600 \mu \mathrm{l}$ of ECM containing 20\% FBS was added. Cells were incubated for $24 \mathrm{~h}$, after which the medium in the upper chamber was discarded. The insert was washed twice with phosphate-buffered saline (PBS), and the cells on the upper membrane were removed using a cotton swab. Cells which had migrated were fixed at room temperature for $30 \mathrm{~min}$, stained with $0.1 \%$ crystal violet for $20 \mathrm{~min}$, washed by PBS three times and observed and imaged under a Olympus CKX41 inverted microscope (magnification x100; Olympus Corp.). Cells were extracted using $100 \mu 110 \%$ acetic acid per pore for $10 \mathrm{~min}$. The optical density (OD) values were measured at $590 \mathrm{~nm}$, and $10 \%$ acetic acid in the blank pores was used as the reference to zero the OD. The inhibition of migration by Tan IIA was calculated as follows: Inhibition rate $=(\mathrm{OD}$ in the positive control group-OD in the Tan IIA dosing group)/OD in the positive control group $\mathrm{x} 100 \%$.

Statistical analysis. Statistical analysis was performed using SPSS version 22.0 (IBM, Corp.). Data are presented as the mean \pm standard deviation of three repeats. If the data passed tests for normality and homogeneity of variance, the one-way ANOVA was applied for statistical inference. If these conditions were not met, a non-parametric test (Wilcoxon rank sum test) was selected. The test used a standard $\alpha=0.05$. P $<0.05$ was considered the threshold for a statistically significant difference.

\section{Results}

$H I F-1 \alpha$ increases the expression of pro-angiogenic factors in HCT-116 cells. In cells infected with the HIF-1 $\alpha$ overexpression lentiviral vector, pGC-FU-HIF-1 $\alpha$, HIF- $1 \alpha$ mRNA expression levels were 5.01 \pm 0.5 times higher compared with the control lentiviral group, and $4.33 \pm 0.15$ times higher compared with the blank group. The protein expression levels of HIF-1 $\alpha$ were also increased significantly $(\mathrm{P}<0.05$; Fig. 1A and B). In cells infected with pGC-FU-HIF-1 $\alpha$, VEGF expression was $426.576 \pm 6.834 \mathrm{pg} / \mathrm{ml}$ compared with 
A

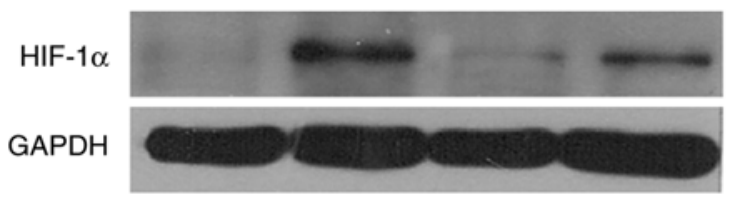

C

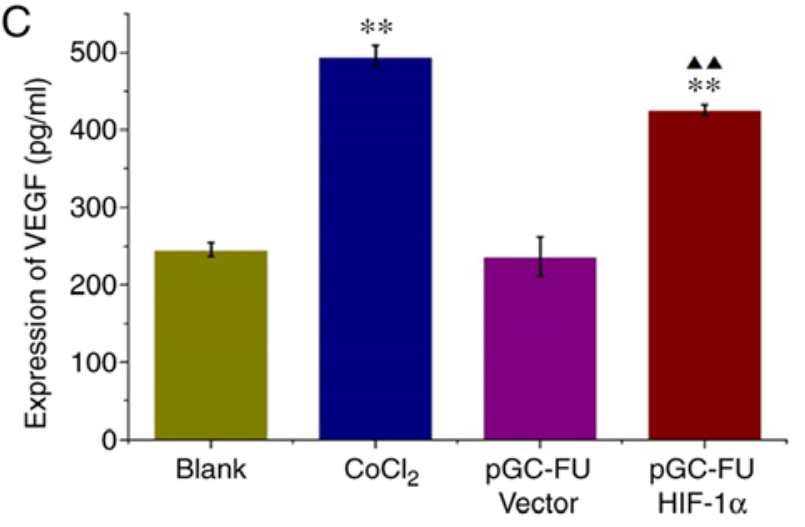

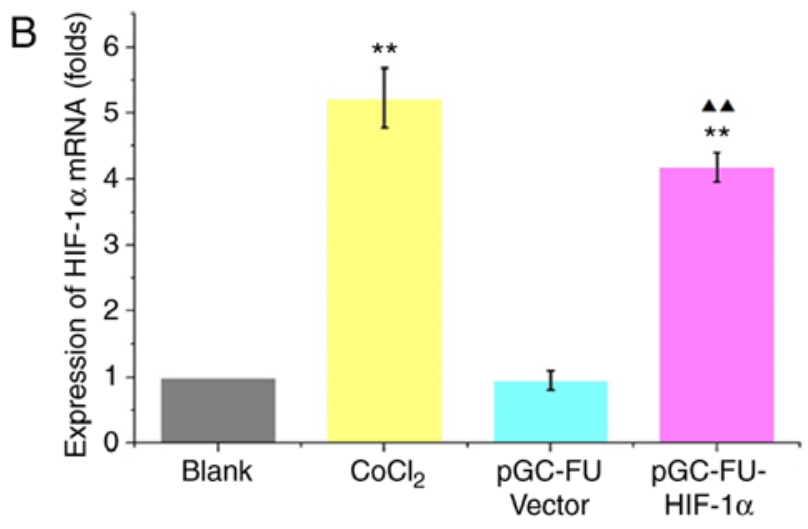

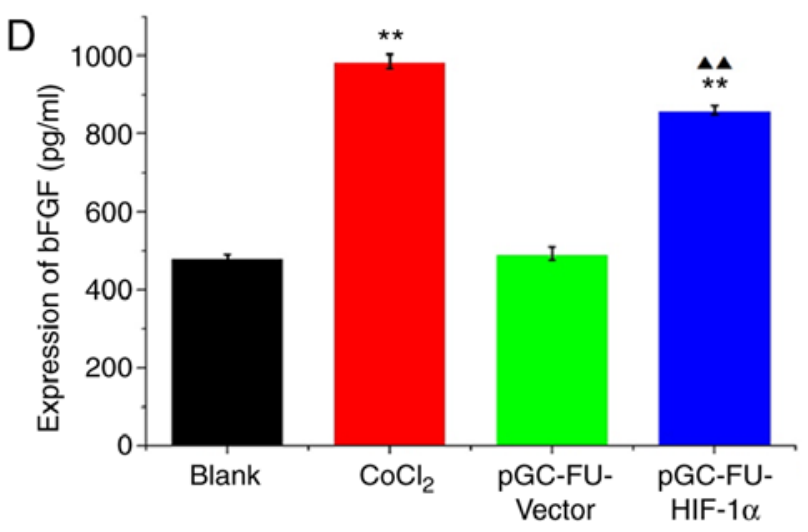

Figure 1. Upregulation of HIF-1 $\alpha$ increases secretion of VEGF and bFGF in HCT-116 cells. (A) Western blot of HIF-1 $\alpha$ levels in HCT-116 cells. (B) HIF-1 $\alpha$ mRNA expression levels were increased under hypoxic conditions and in HIF-1 $\alpha$ overexpression vector-transfected cells. (C) VEGF expression and (D) bFGF expression in the supernatant of HCT-116 cells were analyzed. ${ }^{* *} \mathrm{P}<0.01$ vs. the control, ${ }^{\wedge}{ }^{\wedge} \mathrm{P}<0.01$ vs. the vector control. HIF-1 $\alpha$, hypoxia inducible factor- $1 \alpha$; VEGF, vascular endothelial growth factor; bFGF, basic fibroblast growth factor.

$246.129 \pm 8.948 \mathrm{pg} / \mathrm{ml}$ in the blank group. bFGF expression was $861.39 \pm 11.106 \mathrm{pg} / \mathrm{ml}$ in cells infected with pGC-FU-HIF-1 $\alpha$ compared with $481.872 \pm 9.186 \mathrm{pg} / \mathrm{ml}$ in the blank group. Expression of both VEGF and bFGF were significantly increased compared to the blank group (both $\mathrm{P}<0.01$; Fig. 1C and D) These results indicated that pGC-FU-HIF-1 $\alpha$ increased HIF-1 $\alpha$ expression in HCT-116 cells which in turn increased secretion of VEGF and bFGF.

HIF-1 $\alpha$ interference in HCT-116 cells decreases the expression of VEGF and bFGF under hypoxic conditions. HCT-116 cells were transfected with siR-mimic control plasmid or one of the three HIF-1 $\alpha$ interference plasmids. Hypoxia was simulated using $200 \mu \mathrm{M} \mathrm{CoCl}_{2}$ for $48 \mathrm{~h}$. RT-qPCR and western blotting revealed that HIF-1 $\alpha$ mRNA and protein expression levels were decreased in siR-HIF-1 $\alpha$-transfected cells compared with $\mathrm{CoCl}_{2}$-treated cells and the blank vector group. siR-HIF1 $\alpha$ sequence 3 demonstrated the greatest decrease on expression $(\mathrm{P}<0.01$; Fig. 2A and $\mathrm{B})$ and as such was used in all subsequent experiments. In HCT-116 cells transfected with siRHIF-1 $\alpha$, VEGF expression was $229.725 \pm 15.712 \mathrm{pg} / \mathrm{ml}$ compared with $246.129 \pm 8.948 \mathrm{pg} / \mathrm{ml}$ in the blank group under normal conditions, and this difference was not significant $(\mathrm{P}=0.216$; Fig. $2 \mathrm{C})$. Under hypoxic conditions, VEGF expression was significantly decreased from $495.176 \pm 13.668 \mathrm{pg} / \mathrm{ml}$ in the $\mathrm{CoCl}_{2}$ group compared with $262.533 \pm 22.069 \mathrm{pg} / \mathrm{ml}$ in cells transfected with $\mathrm{CoCl}_{2}+$ siR-HIF1 $\alpha(\mathrm{P}<0.05$; Fig. 2C). bFGF expression under normal conditions was decreased from $478.93 \pm 11.676 \mathrm{pg} / \mathrm{ml}$ in the blank group to $450.981 \pm 11.106 \mathrm{pg} / \mathrm{ml}$ in the siR-HIF1 $\alpha$ group, although the difference was not significant $(\mathrm{P}=0.216$; Fig. 2D). However, under hypoxic conditions, expression of bFGF significantly decreased from $984.954 \pm 18.372 \mathrm{pg} / \mathrm{ml}$ in the $\mathrm{CoCl}_{2}$ group compared with $514.234 \pm 13.239 \mathrm{pg} / \mathrm{ml}$ in cells transfected with $\mathrm{CoCl}_{2}+$ siR-HIF1 $\alpha(\mathrm{P}<0.05$; Fig. 2D). These results indicated that knockdown of HIF-1 $\alpha$ reduced VEGF and bFGF expression under hypoxic conditions but not normal conditions.

Effect of HIF-1 $\alpha$ on tube formation in HUVECs. Under normal conditions, HCT-116 cell culture medium was used to prepare $6.25,12.5,25,50$ and $75 \%$ HCT-116 medium conditioned ECM to simulate the growth environment of a tumor. The media were used to culture HUVECs for 48 h. A CCK-8 assay was used to determine the effect of ECM on the proliferation of HUVECs. The results revealed that excluding the $6.25 \%$ medium, proliferation of HUVECs was significantly increased when conditioned medium was added. Among the various percentages of conditioned media used, the $50 \%$ media resulted in the largest increase in proliferation $(\mathrm{P}<0.01$; Fig. 3A). ECM gel was used to assess the effects of HIF-1 $\alpha$ on tube formation. The results revealed that in the cells grown in medium from HIF-1 $\alpha$ overexpression cells (pGC-FU-HIF- $1 \alpha$ ), tube formation was significantly increased compared with cells grown in medium from either the blank group or pGC-FU-vector group 
A

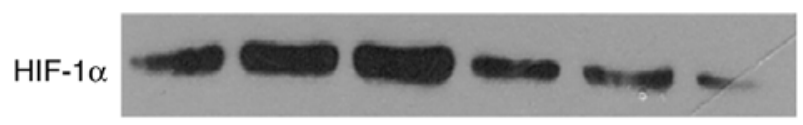

GAPDH

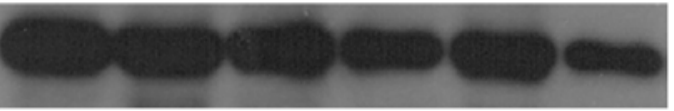

C

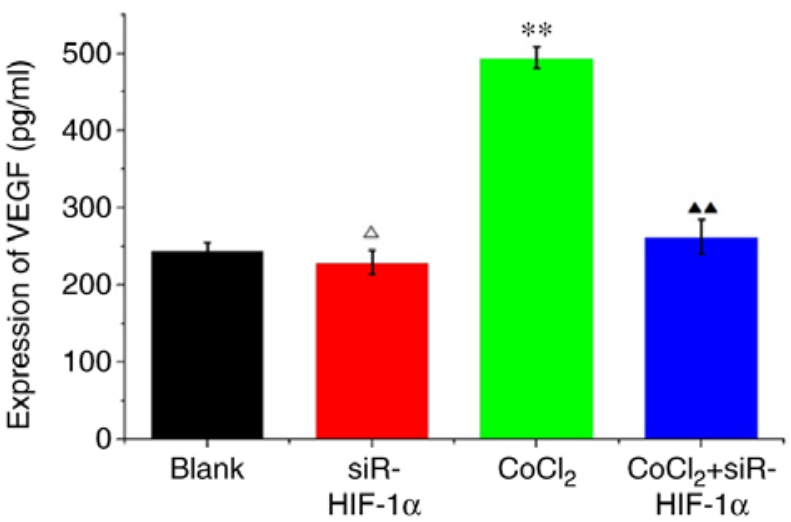

B

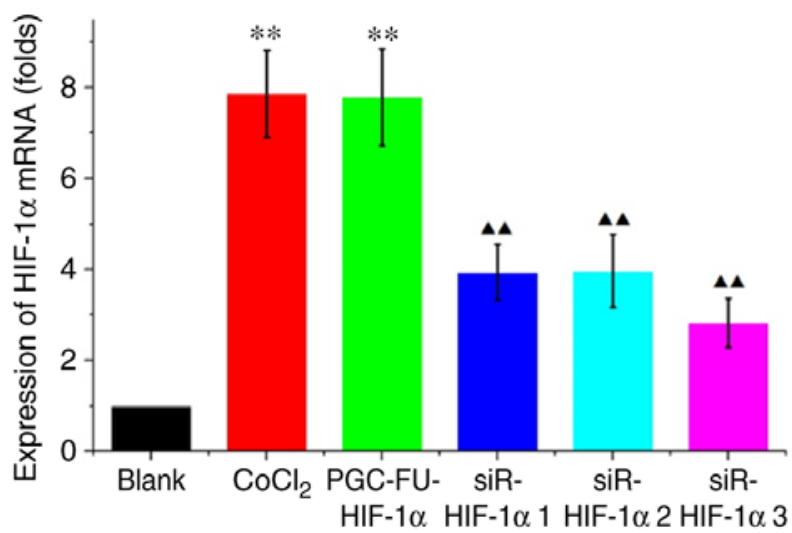

D

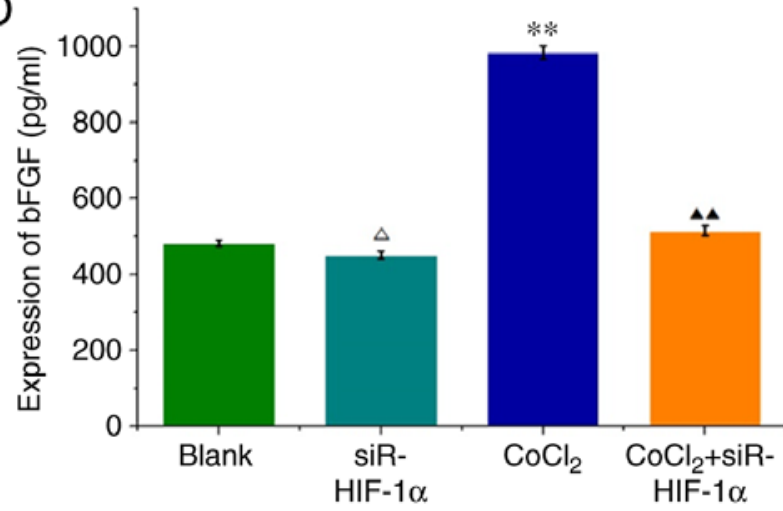

Figure 2. Silencing of HIF-1 $\alpha$ decreases VEGF and bFGF expression under hypoxic conditions in HCT-116 cells. (A) Western blotting of HIF-1 $\alpha$ levels in HCT-116 cells. b-actin was used as the loading control. Three HIF-1 $\alpha$ interference plasmids were used. $\mathrm{Hypoxia}$ was simulated in cells using $200 \mu$ mol/1 $\mathrm{CoCl}{ }_{2}$ (B) HIF-1 $\alpha$ mRNA expression levels were analyzed in HCT-116 cells. The results revealed the fold change in the expression of HIF-1 $\alpha$ normalized to GAPDH. (C) VEGF expression and (D) bFGF expression were analyzed in the supernatant of HCT-116 cells using ELISA under normal and hypoxic conditions. ${ }^{\Delta} \mathrm{P}>0.05$ vs. the normal control; ${ }^{* *} \mathrm{P}<0.01$ vs. the normal control; ${ }^{\mathbf{\Lambda}} \mathrm{P}<0.01$ vs. the hypoxic control. HIF-1 $\alpha$, hypoxia inducible factor-1 $\alpha$; VEGF, vascular endothelial growth factor; bFGF, basic fibroblast growth factor; $\mathrm{CoCl}_{2}$, cobalt chloride.

$(\mathrm{P}<0.01)$. Furthermore, medium from the siR-HIF-1 $\alpha$ group significantly decreased tube formation in HUVECs, and the difference was statistically significant ( $\mathrm{P}<0.05$; Fig. $3 \mathrm{~B}$ and $\mathrm{C}$ ).

Tan IIA decreases proliferation of HCT-116 cells. Under both normal and hypoxic conditions, Tan IIA at different concentrations was added to the HCT-116 cells for 24,48 and $72 \mathrm{~h}$. The results revealed that Tan IIA decreased proliferation of HCT-116 cells in a concentration and time-dependent manner (Fig. 4A and B). Under normal conditions, the $\mathrm{IC}_{50}$ of Tan IIA on HCT-116 cells for 24,48 and $72 \mathrm{~h}$ was $30.7 \pm 1.52,13.3 \pm 0.56$ and $5.1 \pm 0.55 \mu \mathrm{M}$, respectively. Under hypoxic conditions, the $\mathrm{IC}_{50}$ was $8.4 \pm 1.09,2.1 \pm 0.18$ and $0.99 \pm 0.17 \mu \mathrm{M}$, respectively (Fig. 4C and D). Therefore, Tan IIA exhibited a more notable effect on proliferation under hypoxic conditions.

Tan IIA decreases the expression of pro-angiogenic factors under hypoxic conditions. Western blotting and flow cytometry revealed that Tan IIA can significantly decreased HIF-1 $\alpha$ expression in HCT-116 under hypoxic conditions in a concentration dependent manner $(\mathrm{P}<0.01)$. Under hypoxic conditions, $10 \mu \mathrm{M}$ Tan IIA almost completely abrogated $\mathrm{CoCl}_{2}$-induced $\mathrm{HIF}-1 \alpha$ upregulation ( $\mathrm{P}=0.489$; Fig. 5A and B). Similarly, $10 \mu \mathrm{M}$ Tan IIA significantly inhibited secretion of VEGF and bFGF in HCT-116 cells under normal conditions ( $\mathrm{P}<0.05$; Fig. 5C and D). Furthermore, the effects of Tan IIA on secretion of VEGF and
bFGF were notably greater under hypoxic conditions; $10 \mu \mathrm{M}$ of Tan IIA could completely abrogate the $\mathrm{CoCl}_{2}$-induced effects on HIF- $1 \alpha$ expression ( $\mathrm{P}<0.01$; Fig. $5 \mathrm{C}$ and $\mathrm{D})$. siR-HIF- $1 \alpha$ decreased the expression of VEGF and bFGF in cells grown under hypoxic conditions to levels similar to that observed under normal conditions. However, siR-HIF1 $\alpha$ did not affect the expression of VEGF and bFGF under normal conditions (Fig. 5C and D). Tan IIA, significantly decreased the expression levels of VEGF and bFGF in HIF-1 $\alpha$-overexpressing and knockdown cells, (Fig. 5C and D). The results indicated that Tan IIA decreased VEGF and bFGF expression in HCT-116 cells under normal and hypoxic conditions.

Inhibition of tube formation and migration by Tan IIA under hypoxic conditions. A CCK-8 assay revealed that in HUVECs treated with $0.5,1,2,5$ and $10 \mu \mathrm{M}$ Tan IIA HUVECs for 24, 48 and $72 \mathrm{~h}$, proliferation was decreased in a time and concentration dependent manner compared with the control group (Fig. 6A). A tube formation assay revealed that Tan IIA inhibited tube formation in HUVECs in a dose-dependent manner, and $1 \mu \mathrm{M}$ Tan IIA was sufficient to statistically reduce tube formation $(\mathrm{P}<0.01$; Fig. 6B and $\mathrm{C})$. A Transwell migration assay revealed that migration was decreased in cells treated with Tan IIA, and $1 \mu \mathrm{M}$ Tan IIA was sufficient to statistically decrease migration. Tan IIA-mediated inhibition of migration was determined to be concentration-dependent (Fig. 6D and E). 

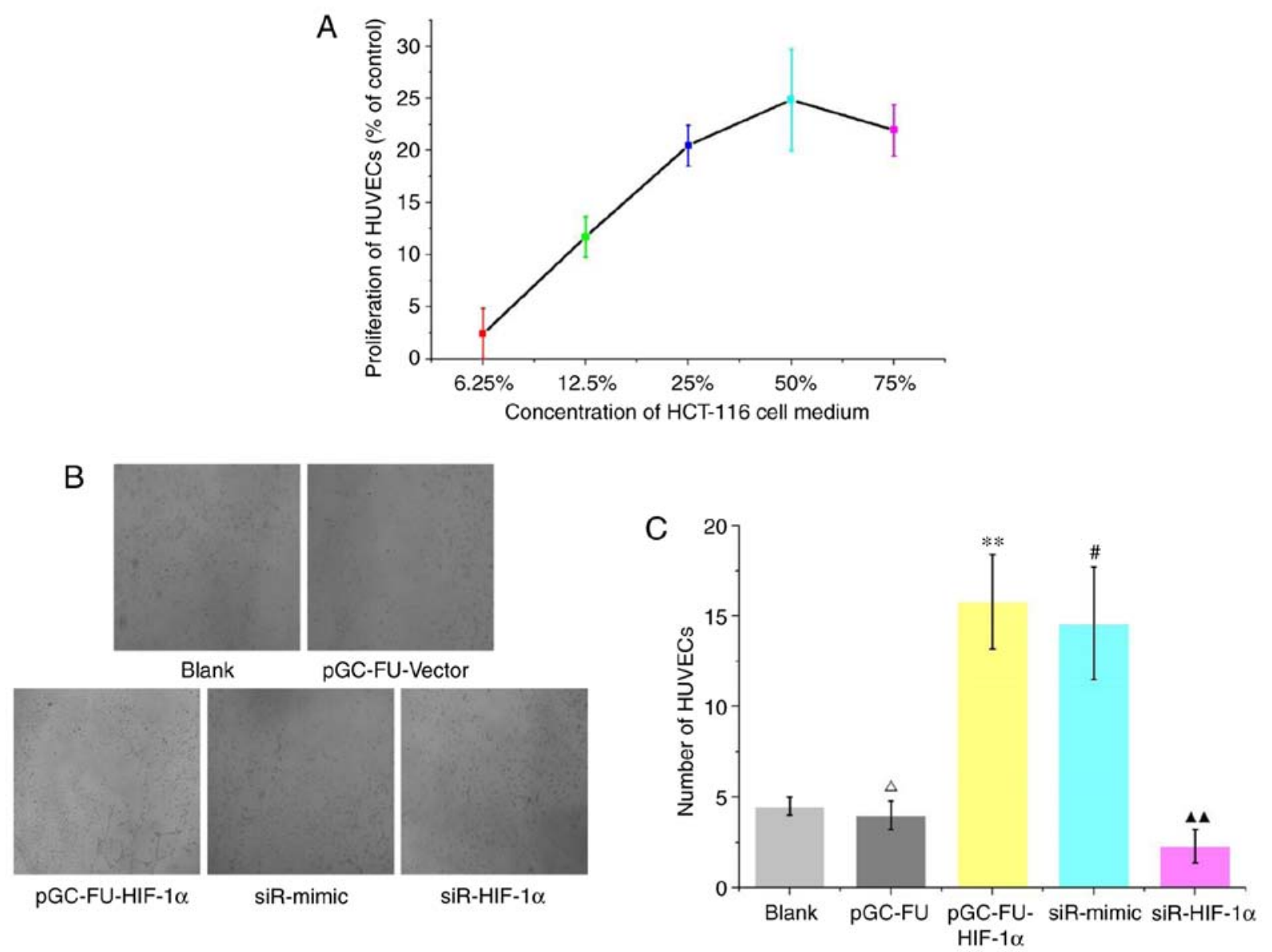

Figure 3. Effect of HIF-1 $\alpha$ expression on tube formation and proliferation of HUVECs. (A) Under normal conditions, the conditioned medium from HCT-116 cells was used to prepare $6.25,12.5,25,50$ and $75 \%$ conditioned endothelial culture medium to simulate the growth environment in colorectal cancer. Proliferation of HUVECs was analyzed using a Cell Counting Kit-8 assay. (B) Tube formation in HUVECs was observed under a microscope in cells where HIF-1 $\alpha$ was overexpressed or silenced. Magnification, $\mathrm{x} 100$. (C) The number of tubes was counted in three fields of view. ${ }^{\Delta} \mathrm{P}>0.05$ vs. the control; ${ }^{* *} \mathrm{P}<0.01$ vs. the control; ${ }^{\#} \mathrm{P}>0.05$ vs. the HIF-1 $\alpha$ overexpression vector; ${ }^{\mathbf{\Lambda}} \mathrm{P}<0.01$ vs. the HIF-1 $\alpha$ overexpression vector. HIF-1 $\alpha$, hypoxia inducible factor-1 $\alpha$; VEGF, vascular endothelial growth factor; bFGF, basic fibroblast growth factor; HUVECs, human umbilical vein endothelial cells.

\section{Discussion}

Tumor angiogenesis serves an important role in the growth, invasion, metastasis and recurrence of CRC. The growth of tumors can be divided into two phases; an avascular phase and an angiogenesis phase (13). Tumors in the avascular phase are in a state of dormancy; whereas in the angiogenesis phase, tumor cells secrete large quantities of pro-angiogenic factors, resulting in rapid growth of tumors. Recent studies demonstrated that a hypoxic microenvironment is the primary factor facilitating the transition of tumors from the avascular phase to the angiogenesis phase (14).

Hypoxia activates a series of pro-angiogenic factors through the aberrant expression of HIF-1 $\alpha$ such that tumors transition to the angiogenesis phase $(15,16)$. Studies have identified numerous signaling molecules which participate in the regulation of tumor angiogenesis $(17,18)$. Among these, VEGF and bFGF are deemed to be the most important angiogenesis factors, and they can promote migration and proliferation of endothelial cells. These factors are closely associated with the growth of tumors and angiogenesis $(18,19)$. VEGF induces proliferation of endothelial cells in vitro, and stimulates chemotaxis of endothelial cell angiogenesis $(20,21)$. bFGF promotes endothelial cell proliferation, stimulates chemotaxis of endo- thelial cells towards tumor tissues and upregulates production of a variety of proteases. bFGF also induces collagen invasion, formation of vessel-like structures and increases the levels of plasminogen activity factor in tissues $(22,23)$.

Hypoxia is a common pathological characteristic observed in solid tumor tissues such as CRC. In poorly differentiated solid tumors, rapid growth accompanied by a lack of adequate vasculature, results in an insufficient blood supply and thus potential lymphatic system disorders. In hypoxia, a number of genes are upregulated in tumor cells in response to hypoxia. HIF-1 $\alpha$ associates with hypoxia response element (HRE), forming the response element binding protein and activating the formation of complexes of other transcription factors. HIF-1 $\alpha$ has been revealed to upregulate expression of VEGF and bFGF $(24,25)$, and upregulation of HIF-1 $\alpha$ in CRC tissues during hypoxic conditions enabled the survival of tumor cells and potentiated evolution of tumors $(26,27)$. Proliferation of endothelial cells underlies the formation of blood vessels and thus is required for angiogenesis, both physiologically and pathophysiologically in tumor tissues. Hypoxia can induce the formation of a large number of new blood vessels through proliferation of endothelial cells. Specifically, hypoxia results in upregulation of HIF-1 $\alpha$, increasing VEGF expression, which promotes angiogenesis. 

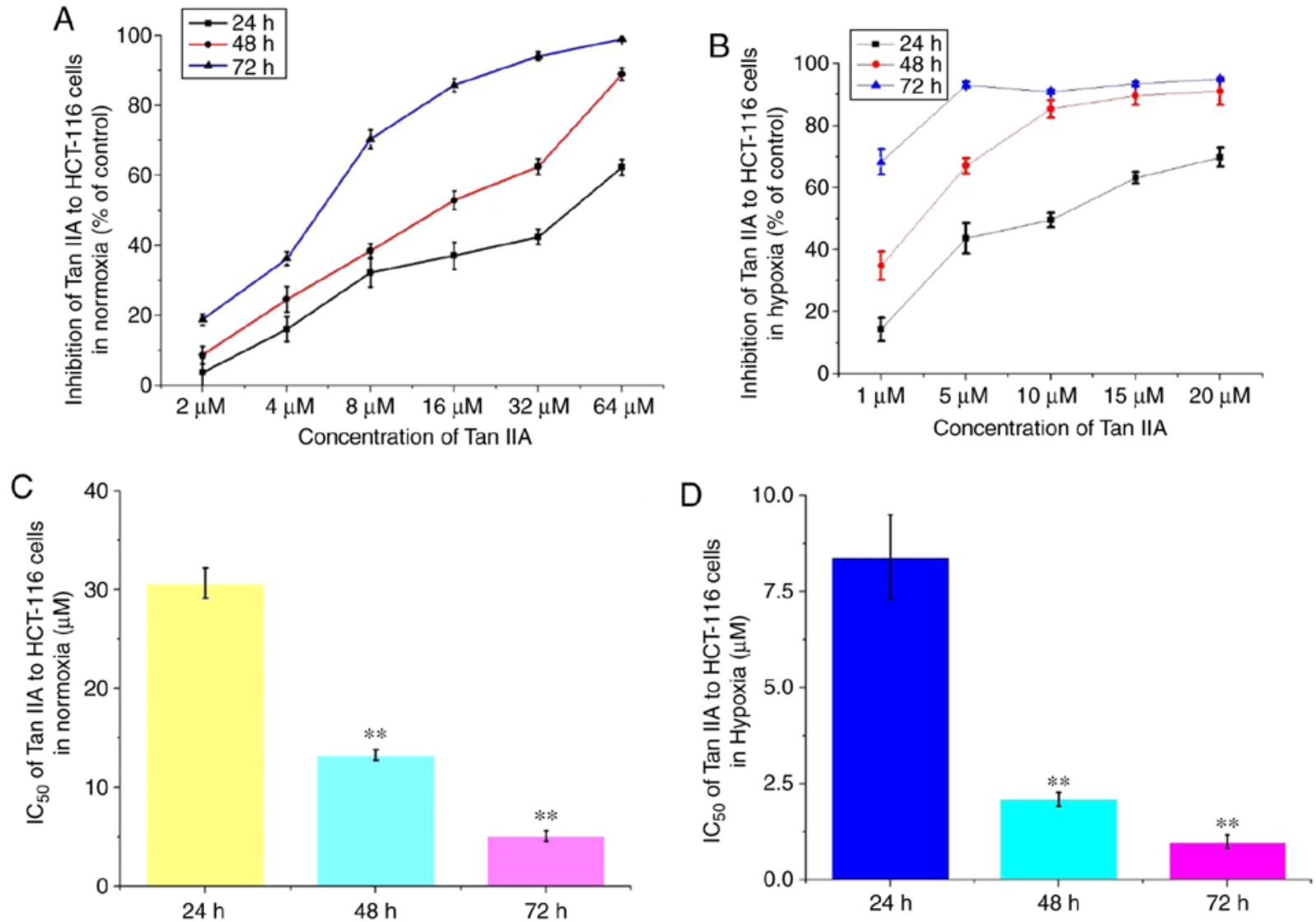

Figure 4. Effects of Tan IIA on the proliferation of HCT-116 under hypoxic conditions. The effects of Tan IIA on proliferation of HCT-116 cell proliferation was analyzed using a Cell Counting Kit-8 assay under (A) normal and (B) hypoxic conditions. Tan IIA was used at a concentration of 2, 4, 8, 16,32 and 64 $\mu \mathrm{M}$ under normal conditions, and 1, 5, 10, 15, 20 and $25 \mu \mathrm{M}$ under hypoxic. $\mathrm{IC}_{50}$ was analyzed in cells treated for 24, 48 and $72 \mathrm{~h}$ under (C) normal and (D) hypoxic conditions. ${ }^{* *} \mathrm{P}<0.01$ vs. $24 \mathrm{~h}$. Tan IIA, tanshinone IIA.

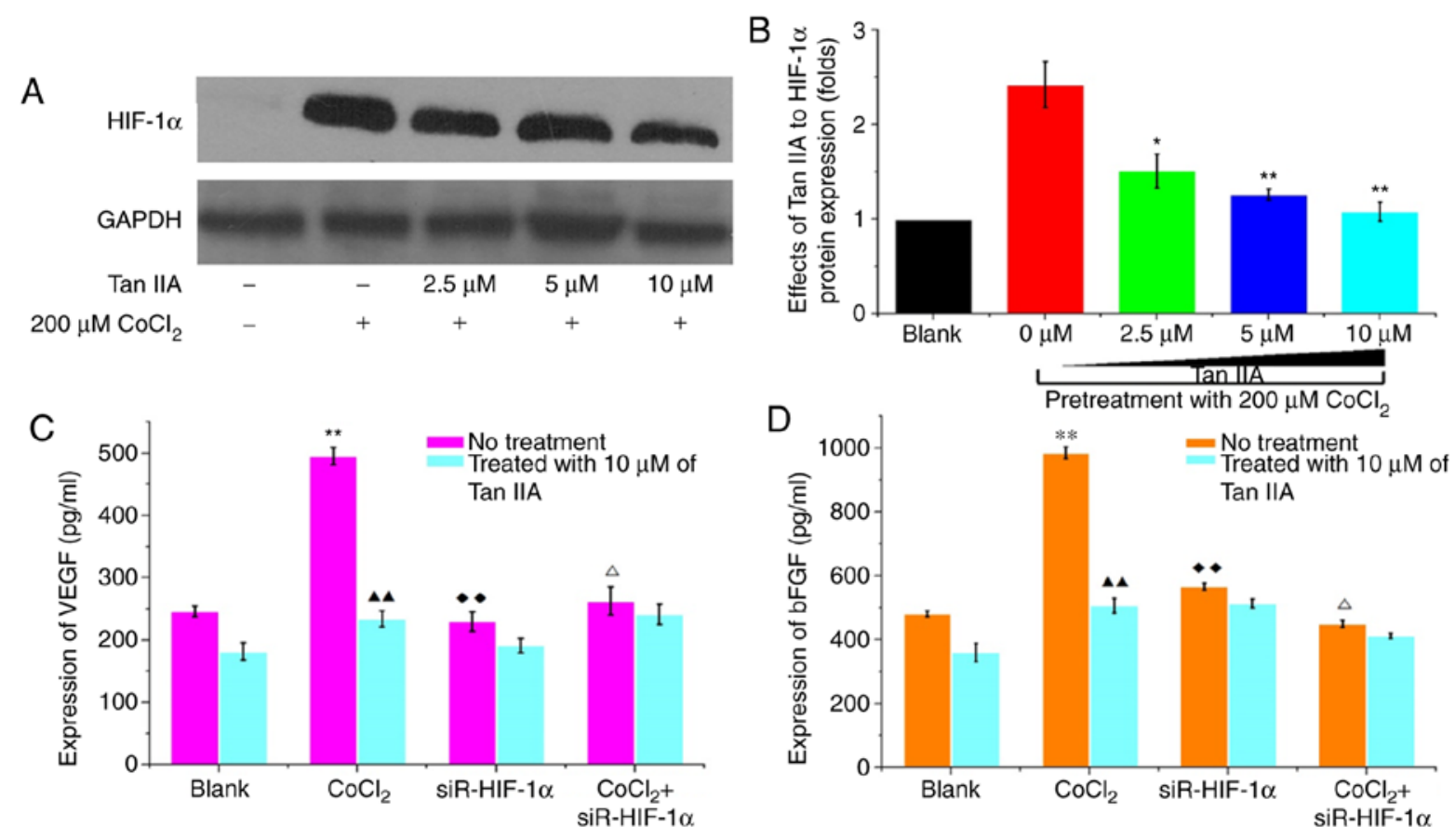

Figure 5. Effects of Tan IIA on the expression of VEGF and bFGF in HCT-116 cells under hypoxic conditions. (A) Western blotting of HIF-1 $\alpha$ levels in HCT-116 cells. b-actin was used as the loading control. To simulate hypoxia, cells were pretreated with $200 \mu \mathrm{M} \mathrm{CoCl}_{2}$ prior to adding $2.5,5$ or $10 \mu \mathrm{M}$ Tan IIA to the HCT-116 cells. (B) HIF-1 $\alpha$ expression was analyzed using flow cytometry in HCT-116 cells. For subsequent experiments, $10 \mu \mathrm{M}$ Tan IIA was used. (C) VEGF and (D) bFGF expression were analyzed using ELISA in the supernatant of HCT-116 cells following overexpression or silencing of HIF-1 $\alpha .{ }^{\Delta} \mathrm{P}>0.05$ vs. the normal control; ${ }^{*} \mathrm{P}<0.05$ vs. the normal control; ${ }^{* *} \mathrm{P}<0.01$ vs. the normal control; ${ }^{\mathbf{\Lambda}} \mathrm{P}<0.01$ vs. the hypoxic control; ${ }^{\bullet} \mathrm{P}<0.01$ vs. the hypoxic control. HIF-1 $\alpha$, hypoxia inducible factor-1 $\alpha$; VEGF, vascular endothelial growth factor; bFGF, basic fibroblast growth factor; $\mathrm{CoCl}_{2}$, cobalt chloride; Tan IIA, tanshinone IIA. 

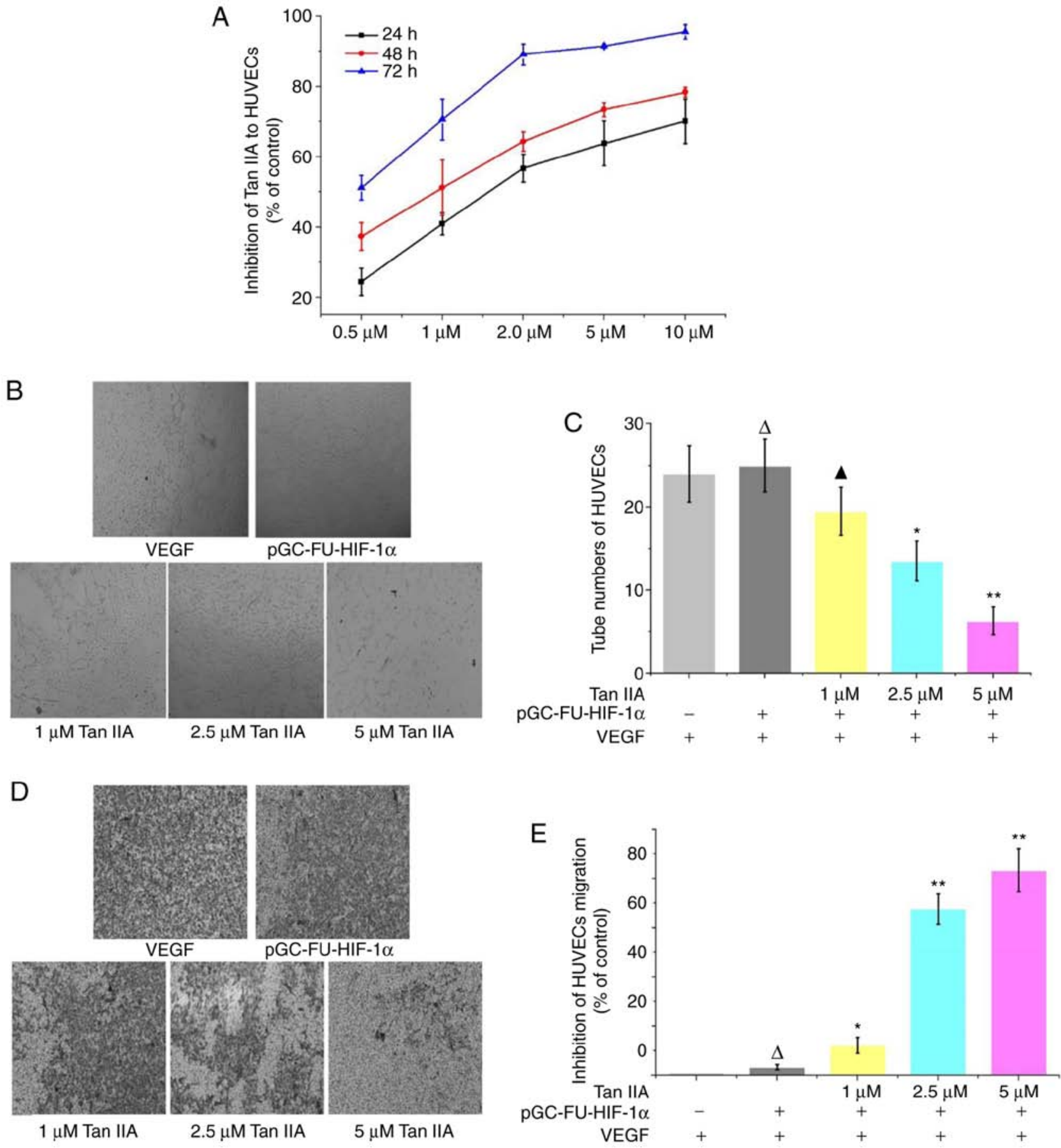

Figure 6. Effects of Tan IIA on tube formation and migration in HUVECs under hypoxic conditions. (A) Proliferation of HUVECs was detected using a Cell Counting Kit- 8 assay. Tan IIA reduced proliferation in a concentration and time-dependent manner. (B) Tube formation in HUVECs overexpressing HIF-1 $\alpha$ treated with 1, 2.5 and $5 \mu \mathrm{M}$ Tan IIA was observed under a microscope. Magnification, x100. (C) The number of tubes formed was counted in three fields of view. ${ }^{\Delta} \mathrm{P}>0.05$ vs. the control; ${ }^{\wedge} \mathrm{P}>0.05$ vs. the control; ${ }^{*} \mathrm{P}<0.05$ vs. the control; ${ }^{* *} \mathrm{P}<0.01$ vs. the control. (D) Migration in HUVECs overexpressing HIF-1 $\alpha$ treated with 1, 2.5 and $5 \mu \mathrm{M}$ Tan IIA was observed under a microscope. Magnification, x100. (E) Effect of Tan IIA on the proliferation of HUVECs was analyzed using a Cell Counting Kit- 8 assay. ${ }^{\mathrm{P}} \mathrm{P}>0.05$ vs. the control; ${ }^{*} \mathrm{P}<0.05$ vs. the control; ${ }^{* *} \mathrm{P}<0.01$ vs. the control. HIF-1 $\alpha$, hypoxia inducible factor- $1 \alpha$; VEGF, vascular endothelial growth factor; bFGF, basic fibroblast growth factor; HUVECs, human umbilical vein endothelial cells; Tan IIA, tanshinone IIA.

In cell experiments, the use of $\mathrm{CoCl}_{2}$ to simulate hypoxia and hypoxia incubators are both effective methods to induce hypoxia, and cells treated with $100 \mu \mathrm{M}$ (28), $200 \mu \mathrm{M}$ (29) or $300 \mu \mathrm{M} \mathrm{(30)} \mathrm{CoCl}_{2}$ are often used as controls. Therefore, $200 \mu \mathrm{M} \mathrm{CoCl}_{2}$ was used in this experiment to simulate hypoxia, and this method could effectively induce hypoxia. A hypoxic cell incubator, as another method to simulate hypoxia, cannot be the limitation of the use of $\mathrm{CoCl}_{2}$ in this study.
The promoter region of VEGF and the regulating gene region of bFGF contains an HRE, and HIF- $1 \alpha$ can bind to the response element, thus directly regulating the expression of VEGF and bFGF at the genetic level $(31,32)$. In the present study, ELISA was used to determine the effects of regulating HIF-1 $\alpha$ expression on the secretion of VEGF and bFGF in the supernatant of CRC cells. HIF-1 $\alpha$ significantly increased the expression levels of VEGF and bFGF. However, during normal 
conditions, targeted interference of HIF-1 $\alpha$ did not result in a decrease of VEGF expression. In $\mathrm{CoCl}_{2}$-simulated hypoxia, VEGF expression was significantly reduced. Additionally, bFGF expression was regulated by HIF-1 $\alpha$. Both under normal conditions and $\mathrm{CoCl}_{2}$-simulated hypoxia, silencing the HIF-1 $\alpha$ gene resulted in a decrease in bFGF expression. These findings indicated that upregulation and interference of HIF-1 $\alpha$ expression regulated VEGF and bFGF expression in HCT-116 cells, and may therefore regulate angiogenesis in CRC.

HUVEC tube formation, clonogenic assays and BrdU assays are commonly used experimental methods, among which HUVEC tube formation is a classical method for angiogenesis research (33). In the present study, this method was applied as a functional research method for Tan IIA to inhibit angiogenesis in colorectal cancer. Interactions between tumor cells and endothelial cells result in tumor angiogenesis, tumor cells recruit endothelial cells and endothelial cells of the blood vessels stimulate growth and proliferation of tumor cells through paracrine effects (34). The present study demonstrated that HIF-1 $\alpha$ overexpression significantly increased proliferation of HUVECs. Tube formation was increased in HUVECs when HIF-1 $\alpha$ was overexpressed compared to cells where HIF-1 $\alpha$ was knocked down. However, in cells where HIF-1 $\alpha$ was knocked down tube formation was further reduced in hypoxic conditions.

Tan IIA exhibits antineoplastic activity in a variety of malignancies, such as hepatic (35), gastric (36) and colorectal cancer (37), although the underlying mechanism has not been determined. In our previous studies $(10,11)$, high-doses of Tan IIA significantly inhibited proliferation in CRC cells and decreased VEGF expression through regulation of COX-2 expression. This suggests that Tan IIA may efficiently reduce expression of angiogenesis-promoting factors, and this may underlie its antineoplastic effects. In the present study, Tan IIA significantly decreased proliferation of HCT-116 cells under hypoxic conditions in a time- and concentration-dependent manner. Tan IIA also significantly decreased expression of HIF-1 $\alpha$ induced by hypoxia. Therefore, based on these results it was hypothesized that Tan IIA may decrease the expression of HIF-1 $\alpha$ in HCT-116 cells under hypoxic conditions. ELISA revealed that Tan IIA decreased the expression levels of VEGF and bFGF in the HCT-116 cells. Additionally, the effects of Tan IIA on VEGF and bFGF secretion were more prominent in cells in which hypoxia was induced using $200 \mu \mathrm{M} \mathrm{CoCl}_{2}$. Treatment with $10 \mu \mathrm{M}$ Tan IIA reversed upregulation of VEGF and bFGF induced by $\mathrm{CoCl}_{2}$. In cells where HIF-1 $\alpha$ was silenced, the effects of Tan IIA on reduction of VEGF and bFGF were increased.

The anti-proliferative effects of Tan IIA on HUVECs revealed that Tan IIA effectively inhibited proliferation of HUVECs. The median inhibitory concentration at 24, 48 and $72 \mathrm{~h}$ was $1.65,0.99$ and $0.36 \mu \mathrm{M}$, respectively. Tube formation and migration assays with HUVECs revealed that $1 \mu \mathrm{M}$ of Tan IIA inhibited tube formation and metastasis in HUVECs. This suggests that Tan IIA directly inhibited proliferation, tube formation and metastasis of endothelial cells, and may prevent angiogenesis in CRC. The present study demonstrated that Tan IIA inhibited secretion of pro-angiogenic factors under hypoxic conditions through downregulation of HIF-1 $\alpha$ expression and also directly inhibited proliferation, tube formation and metastasis of HUVECs. This suggests that HIF-1 $\alpha$ and its effects on angiogenesis are potential targets for preventing progression and metastasis of CRC.

In summary, HIF-1 $\alpha$ may serve as a potential target in CRC and Tan IIA may be used to inhibit angiogenesis in CRC cells under normal and hypoxic conditions by modulating the tumor hypoxia microenvironment.

\section{Acknowledgements}

Not applicable.

\section{Funding}

The present study was supported by the National Natural Science Foundation of China (grant nos. 81673784, $81673783,81874405,81973651$ and 81520108031), The Science Foundation for Shanghai Committee of Science Project (grant nos. 18QA1404200 and 17QA1404100), The Shanghai Health Bureau Science Foundation [grant no. ZY(2018-2020)-FWTX-4026], the Shang Youth Medical Talents Training Program (grant no. 2017YQ077) and the Xinglin Young Scholar, Shanghai University of Traditional Chinese Medicine.

\section{Availability of data and materials}

The datasets used and/or analyzed during the present study are available from the author on reasonable request.

\section{Authors' contributions}

YL, QL, and BZ designed the study. LZ and HS performed the majority of the cell-based experiments with help from TW, RJ, ZZ, YF, NL, JF, YW and QJ. BZ and NL performed the data management and statistical analysis. LZ, HS, QL and YL wrote the manuscript. All authors read and approved the manuscript and agree to be accountable for all aspects of the research in ensuring that the accuracy or integrity of any part of the work are appropriately investigated and resolved.

\section{Ethics approval and consent to participate}

Not applicable.

\section{Patient consent for publication}

Not applicable.

\section{Competing interests}

The authors declare that they have no competing interests.

\section{References}

1. Torre LA, Bray F, Siegel RL, Ferlay J, Lortet-Tieulent J and Jemal A: Global Cancer Statistics, 2012. CA Cancer J Clin 65: 87-108, 2015.

2. Deenen MJ, Meulendijks D, Cats A, Sechterberger MK, Severens JL, Boot H, Smits PH, Rosing H, Mandigers CM, Soesan M, et al: Upfront genotyping of DPYD*2A to individualize fluoropyrimidine therapy: A safety and cost analysis. J Clin Oncol 34: 227-234, 2016. 
3. Yamano T, Yoshimura M, Kobayashi M, Beppu N, Hamanaka M, Babaya A, Tsukamoto K, Noda M, Matsubara N and Tomita N: Malnutrition in rectal cancer patients receiving preoperative chemoradiotherapy is common and associated with treatment tolerability and anastomotic leakage. Int J Colorectal Dis 31: 877-884, 2016.

4. Ramjiawan RR, Griffioen AW and Duda DG: Anti-angiogenesis for cancer revisited: Is there a role for combinations with immunotherapy? Angiogenesis 20: 185-204, 2017.

5. Viallard $C$ and Larrivée B: Tumor angiogenesis and vascular normalization: Alternative therapeutic targets. Angiogenesis 20: 409-426, 2017

6. Zhu H, Li X, Yuan M, Wan W, Hu M, Wang X and Jiang X: Intramyocardial delivery of bFGF with a biodegradable and thermosensitive hydrogel improves angiogenesis and cardio-protection in infarcted myocardium. Exp Ther Med 14 3609-3615, 2017.

7. Zeng M, Shen J, Liu Y, Lu LY, Ding K, Fortmann SD, Khan M, Wang J, Hackett SF, Semenza GL and Campochiaro PA The HIF-1 antagonist acriflavine: Visualization in retina and suppression of ocular neovascularization. J Mol Med (Berl) 95: 417-429, 2017.

8. OhET, Kim CW, Kim HG, Lee JS and Park HJ: Brusatol-mediated inhibition of c-Myc increases HIF-1 $\alpha$ degradation and causes cell death in colorectal cancer under hypoxia. Theranostics 7 : 3415-3431, 2017.

9. Kasai M, Van Damme N, Berardi G, Geboes K, Laurent S and Troisi RI: The inflammatory response to stress and angiogenesis in liver resection for colorectal liver metastases: A randomized controlled trial comparing open versus laparoscopic approach. Acta Chir Belg 118: 172-180, 2018.

10. Sui H, Zhao J, Zhou L, Wen H, Deng W, Li C, Ji Q, Liu X, Feng Y, Chai $\mathrm{N}$, et al: Tanshinone IIA inhibits $\beta$-catenin/VEGF-mediated angiogenesis by targeting TGF- $\beta 1$ in normoxic and HIF- $1 \alpha$ in hypoxic microenvironments in human colorectal cancer. Cancer Lett 403: 86-97, 2017.

11. Zhou LH, Hu Q, Sui H, Ci SJ, Wang Y, Liu X, Liu NN, Yin PH, Qin JM and Li Q: Tanshinone II-a inhibits angiogenesis through down regulation of COX-2 in human colorectal cancer. Asian Pac J Cancer Prev 13: 4453-4458, 2012.

12. Livak KJ and Schmittgen TD: Analysis of relative gene expression data using real-time quantitative PCR and the 2(-Delta Delta C(T)) method. Methods 25: 402-408, 2001.

13. Salavati H, Soltani M and Amanpour S: The pivotal role of angiogenesis in a multi-scale modeling of tumor growth exhibiting the avascular and vascular phases. Microvasc Res 119: 105-116, 2018.

14. Huang WC, Chen SH, Chiang WH, Huang CW, Lo CL, Chern CS and Chiu HC: Tumor microenvironment-responsive nanoparticle delivery of chemotherapy for enhanced selective cellular uptake and transportation within tumor. Biomacromolecules 17 3883-3892, 2016.

15. Lequeux A, Noman MZ, Xiao M, Sauvage D, Van Moer K, Viry E, Bocci I, Hasmim M, Bosseler M, Berchem G and Janji B: Impact of hypoxic tumor microenvironment and tumor cell plasticity on the expression of immune checkpoints. Cancer Lett 458: $13-20,2019$.

16. Belluco C, Forlin M, Delrio P, Rega D, Degiuli M, Sofia S, Olivieri M, Pucciarelli S, Zuin M, De Manzoni G, et al: Elevated platelet count is a negative predictive and prognostic marker in locally advanced rectal cancer undergoing neoadjuvant chemoradiation: A retrospective multi-institutional study on 965 patients. BMC Cancer 18: 1094, 2018.

17. Pastorekova $S$ and Gillies RJ: The role of carbonic anhydrase IX in cancer development: Links to hypoxia, acidosis, and beyond. Cancer Metastasis Rev 38: 65-77, 2019.

18. Broggini T, Wüstner M, Harms C, Stange L, Blaes J, Thomé C, Harms U, Mueller S, Weiler M, Wick W, et al: NDRG1 overexpressing gliomas are characterized by reduced tumor vascularization and resistance to antiangiogenic treatment. Cancer Lett 380: 568-576, 2016.

19. Zhu CC, Chen C, Xu ZQ, Zhao JK, Ou BC, Sun J, Zheng MH, Zong YP and Lu AG: CCR6 promotes tumor angiogenesis via the AKT/NF- $\mathrm{BB} / \mathrm{VEGF}$ pathway in colorectal cancer. Biochim Biophys Acta Mol Basis Dis 1864: 387-397, 2018.

20. Barravecchia I, Mariotti S, Pucci A, Scebba F, De Cesari C, Bicciato S, Tagliafico E, Tenedini E, Vindigni C, Cecchini M, et al: MICAL2 is expressed in cancer associated neo-angiogenic capillary endothelia and it is required for endothelial cell viability, motility and VEGF response. Biochim Biophys Acta Mol Basis Dis 1865: 2111-2124, 2019.
21. Xu J, Liu M, Yu M, Shen J, Zhou J, Hu J, Zhou Y and Zhang W: RasGRP1 is a target for VEGF to induce angiogenesis and involved in the endothelial-protective effects of metformin under high glucose in HUVECs. IUBMB Life 71: 1391-1400, 2019.

22. Wang HJ and Lo WY: Identification of basic fibroblast growth factor as the dominant protector of laminar shear medium from the modified shear device in tumor necrosis factor- $\alpha$ induced endothelial dysfunction. Front Physiol 8: 1095, 2017.

23. Han JH, Hwang AR, Nam DH, Kim S, Choi HC, Lim JH and Woo CH: ERK 5 regulates basic fibroblast growth factor-induced type 1 plasminogen activator inhibitor expression and cell proliferation in lung fibroblasts. Life Sci 135: 1-8, 2015.

24. Meng L, Cheng Y, Tong X, Gan S, Ding Y, Zhang Y, Wang C, $\mathrm{Xu} \mathrm{L}, \mathrm{Zhu} \mathrm{Y}, \mathrm{Wu}$ J, et al: Tumor oxygenation and hypoxia inducible factor- 1 functional inhibition via a reactive oxygen species responsive nanoplatform for enhancing radiation therapy and abscopal effects. ACS Nano 12: 8308-8322, 2018.

25. Deng Y, Huang G, Chen F, Testroet ED, Li H, Li H, Nong T, Yang X, Cui J, Shi D and Yang S: Hypoxia enhances buffalo adipose-derived mesenchymal stem cells proliferation, stemness, and reprogramming into induced pluripotent stem cells. J Cell Physiol 234: 17254-17268, 2019.

26. Han J, Jackson D, Holm J, Turner K, Ashcraft P, Wang X, Cook B, Arning E, Genta RM, Venuprasad K, et al: Elevated d-2-hydroxyglutarate during colitis drives progression to colorectal cancer. Proc Natl Acad Sci USA 115: 1057-1062, 2018.

27. Ni T, He Z, Dai Y, Yao J, Guo Q and Wei L: Oroxylin A suppresses the development and growth of colorectal cancer through reprogram of HIF1 $\alpha$-modulated fatty acid metabolism. Cell Death Dis 8: e2865, 2017.

28. Bharti R, Dey G, Das AK and Mandal M: Differential expression of IL-6/IL-6R and MAO-A regulates invasion/angiogenesis in breast cancer. Br J Cancer 118: 1442-1452, 2018

29. Liu Y, Xu S, Zu T, Li F, Sang S, Liu C, An Y, Mi B, Orgill DP, Murphy GF and Lian CG: Reversal of TET-mediated 5-hmC loss in hypoxic fibroblasts by ascorbic acid. Lab Invest 99: 1193-1202, 2019.

30. Maliha AM, Kuehn S, Hurst J, Herms F, Fehr M, Bartz-Schmidt KU, Dick HB, Joachim SC and Schnichels S: Diminished apoptosis in hypoxic porcine retina explant cultures through hypothermia. Sci Rep 9: 4898, 2019.

31. Kobayashi M, Morinibu A, Koyasu S, Goto Y, Hiraoka M and Harada H: A circadian clock gene, PER2, activates HIF-1 as an effector molecule for recruitment of HIF- $1 \alpha$ to promoter regions of its downstream genes. FEBS J 284: 3804-3816, 2017.

32. Fu X, Zhai S and Yuan J: Interleukin-6 (IL-6) triggers the malignancy of hemangioma cells via activation of HIF-1 $\alpha$ /VEGFA signals. Eur J Pharmacol 841: 82-89, 2018

33. Zhang M, Qiu L, Zhang Y, Xu D, Zheng JC and Jiang L: CXCL12 enhances angiogenesis through CXCR7 activation in human umbilical vein endothelial cells. Sci Rep 7, 8289, 2017.

34. Batlle R, Andrés E, Gonzalez L, Llonch E, Igea A, Gutierrez-Prat N, Berenguer-Llergo A and Nebreda AR: Regulation of tumor angiogenesis and mesenchymal-endothelial transition by $\mathrm{p} 38 \alpha$ through TGF- $\beta$ and JNK signaling. Nat Commun 10: 3071, 2019.

35. Ren X, Wang C, Xie B, Hu L, Chai H, Ding L, Tang L, Xia Y and Dou X: Tanshinone IIA induced cell death via miR30b-p53-PTPN11/SHP2 signaling pathway in human hepatocellular carcinoma cells. Eur J Pharmacol 796: 233-241, 2017.

36. Xu Z, Chen L, Xiao Z, Zhu Y, Jiang H, Jin Y, Gu C, Wu Y, Wang L, Zhang W, et al: Potentiation of the anticancer effect of doxorubicinin drug-resistant gastric cancer cells by tanshinone IIA. Phytomedicine 51: 58-67, 2018.

37. Qian J, Fang D, Lu H, Cao Y, Zhang J, Ding R, Li L and Huo J: Tanshinone IIA promotes IL2-mediated SW480 colorectal cancer cell apoptosis by triggering INF2-related mitochondrial fission and activating the Mst1-Hippo pathway. Biomed Pharmacother 108: 1658-1669, 2018.

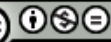

This work is licensed under a Creative Commons Attribution-NonCommercial-NoDerivatives 4.0 International (CC BY-NC-ND 4.0) License. 